\title{
Marital status and survival following bladder cancer
}

\section{Citation}

Datta, G D., B A Neville, I Kawachi, N S Datta, and C C Earle. 2009. "Marital Status and Survival Following Bladder Cancer." Journal of Epidemiology \& Community Health 63 (10): 807-13. https://doi.org/10.1136/jech.2008.082438.

\section{Permanent link}

http://nrs.harvard.edu/urn-3:HUL.InstRepos:41288121

\section{Terms of Use}

This article was downloaded from Harvard University's DASH repository, and is made available under the terms and conditions applicable to Other Posted Material, as set forth at http:// nrs.harvard.edu/urn-3:HUL.InstRepos:dash.current.terms-of-use\#LAA

\section{Share Your Story}

The Harvard community has made this article openly available.

Please share how this access benefits you. Submit a story.

Accessibility 


\section{Marital Status and Survival Following Bladder Cancer}

Authors:

Geetanjali Dabral Datta, Sc.D, M.P.H. - Research Associate, Harvard School of Public Health and Visiting Scientist, INSERM U558 Paul Sabatier University

Bridget A. Neville, M.P.H. - Analyst, Dana-Farber Cancer Institute Ichiro Kawachi, M.D., Ph.D. - Professor, Harvard School of Public Health, Department of Society, Human Development and Health and the Center for Society and Health Nand S. Datta, M.D. - Associate Professor, University of California, Los Angeles Craig C. Earle, M.D., M.Sc. - Director, Health Services Research Program, Cancer Care Ontario and Ontario Institute for Cancer Research

Corresponding Author:

Geetanjali Dabral Datta

Paul Sebatier University

Faculty of Medicine

37 Allée Jules Guesde

Toulouse, France 31073

Phone : +33 (0)6 34964602

E-mail: gddatta@gmail.com 
Sources of support: This project was supported by grants from the National Cancer Institute (CA 91753-02) and the Robert Wood Johnson Foundation. At the time the project was complete Dr. G.D. Datta was supported by the W.K. Kellogg Fellowship in Health Disparities and the Alonzo Smythe Yerby Postdoctoral Fellowship.

Disclosure: There are no financial disclosures from any authors.

Acknowledgement: The authors would like to thank Dr. Maria Glymour for reviewing an earlier version of the manuscript.

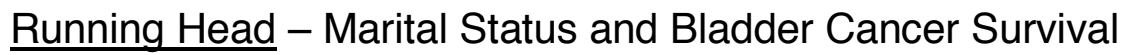

Medical Subject Headings (MeSH)(Keywords): Urinary Bladder Neoplasms, Mortality, Marital Status, Outcomes Assessment

\section{What this paper adds}

What is already known on this subject?

Previous studies indicate marital status influences survival after diagnosis with bladder cancer. However, the possible mechanisms for this association are largely unstudied.

What does his study add?

The results of the current study suggest a lack of evidence of mediation of the association between marital status and survival through treatment, comorbidities, ecologic SES, or receiving treatment at a teaching hospital among the majority of married men and women suggesting they may be benefiting from something other than these factors, perhaps practical or social support. This association may be stronger for men than for women.

Number of text pages $=25$ 
Number of tables $=4$ (including 1 appendix table)

Number of figures $=1$

Word count $=3344$

Licence for Publication statement

The Corresponding Author has the right to grant on behalf of all authors and does grant on behalf of all authors, an exclusive licence on a worldwide basis to the BMJ

Publishing Group Ltd to permit this article (if accepted) to be published in JECH and any other BMJPGL products and sublicenses such use and exploit all subsidiary rights, as set out in our licence (http://jech.bmj.com/ifora/licence.pdf). 


\section{Abstract (Word count $=202$ )}

Background: Marital status has been implicated as a prognostic factor in bladder cancer survival. However, few studies have explored potential mechanisms through which this might occur.

Methods: We identified 19,982 bladder cancer patients from the SEER-Medicare database (1992-1998) and constructed sex-specific Cox proportional hazard models to assess the relation between marital status and 5-year survival while sequentially adding covariates to test possible mechanisms.

Results: Multivariable Cox analyses suggest that at every stage, married men had better survival than unmarried men independent of age, race, ecologic socioeconomic status, comorbidities, any or aggressive treatment (assessed separately), and accessing a teaching hospital (Hazard Ratio $[\mathrm{HR}]=0.80,95 \%$ Confidence Interval $[\mathrm{Cl}]=$ 0.74-0.87). Among women with stages II-IV bladder cancer, age and the presence of comorbid conditions explained the association between marital status and survival. However, among those diagnosed with stage I bladder cancer, none of the covariates explained the association between marital status and decreased mortality (Fullyadjusted $\mathrm{HR}=0.72,95 \% \mathrm{Cl}=0.62-0.84)$.

Conclusion: The lack of evidence of mediation through treatment, overall health, SES, or quality of health-care institution among married men and women with stage I disease suggests they may be benefiting from something other than these factors, perhaps practical or social support. 


\section{Introduction}

As the American population ages, it is increasingly important to develop interventions to decrease morbidity and mortality in the elderly. Those who are married have been found to have decreased all-cause mortality ${ }^{1,2}$ and understanding how marriage influences survival may inform ways in which those who are unmarried can also increase their longevity.

Marital status is associated with survival after diagnosis with several types of cancer $^{3-6}$ including that of the bladder. ${ }^{7}$ The incidence and mortality rates for bladder cancer in the United States (US) are $20.7 / 100,000$ and 4.4/100,000 respectively, ${ }^{8}$ and in 2008 an estimated 68,810 individuals were diagnosed with and 14,100 died from the disease. ${ }^{9}$ A recent study reported that married bladder cancer patients in the US had a $20 \%$ increased survival in comparison with single patients and $44 \%$ increased survival in comparison with widowed patients. ${ }^{7}$ In a study conducted in Norway, researchers found no association between marital status and bladder cancer survival among women, but found an association in men. ${ }^{6}$

There are several proposed mechanisms to explain the association between cancer survival and marital status. Those who are married may enjoy increased financial resources, may experience improved practical or social support, may be more risk averse, may have a healthier life-style, may receive better treatment than those who are unmarried, ${ }^{1}$ or receive treatment at higher quality hospitals. ${ }^{10}$

It is unknown which mechanisms explain the increased survival from bladder cancer among those who are married and it is also unknown if those mechanisms differ 
by gender. To address these issues, we identified bladder cancer patients from the SEER-Medicare database and assessed the association between marital status and 5year survival while accounting for sex, stage, age, race, socioeconomic status, comorbid condictions, any treatment, aggressive treatment, and accessing a teaching hospital.

\section{Materials and Methods}

Study Population

The dataset consisted of 19,982 Medicare insured bladder cancer patients diagnosed between 1992 and 1998 in one of 11 Surveillance Epidemiology and End Results (SEER) areas. The SEER program is a collection of cancer registries that report diagnoses, demographic information, and cause of death for people residing in discrete geographic areas and represents approximately $14 \%$ of the US population. ${ }^{11}$ Details on the SEER program, SEER-Medicare linkage, and Medicare eligibility requirements have been described elsewhere. ${ }^{12}$

Cases with International Classification of Disease for Oncology codes C67.0 C67.9 were eligible for inclusion in the study. Ninety-three percent of bladder cancers are transitional cell carcinomas, ${ }^{13}$ thus we restricted our analyses to this disease subtype. Those with missing marital status $(n=508)$ or tumor stage $(n=746)$ data were excluded from the analysis.

Patients were followed through 2003 to assess 5-year mortality. Cases were excluded if patients were eligible for Medicare due to end-stage renal disease or disability $(n=1728)$, if bladder cancer was not the patient's first cancer $(n=1222)$, if 
diagnosis was obtained from death certificate or autopsy ( $n=170)$, or if SEER and Medicare death dates were more than 3 months apart $(n=84)$.

Marital status was ascertained from hospital records at the time of diagnosis by the SEER program. As $88 \%$ of our population was either married or single, and statistics show that those who are married have lower age-adjusted mortality rates than those who are never married, widowed, or divorced, ${ }^{2}$ we dichotomized marital status into married and unmarried.

\section{Stage and Grade}

Tumors were classified using the American Joint Committee on Cancer (AJCC) TNM staging system. Superficial, or stage I, bladder cancer is a heterogeneous group of tumors with differing likelihood of progression. ${ }^{14}$ They can be considered low-, moderate-, or high-risk depending on tumor characteristics. This distinction is useful in guiding treatment and post-treatment surveillance. ${ }^{13}$ Among low-risk tumors, 50-75\% reoccur, but only $2-5 \%$ progress. Among moderate- to high-risk tumors, approximately $75 \%$ reoccur and $30-50 \%$ progress to invasive disease. ${ }^{13,15}$ SEER data contain a field which codes for the extent of disease (EOD). We used the EOD codes in conjunction with the SEER Program Code Manual (1998), ${ }^{16}$ the AJCC Cancer Staging Manual (2002),${ }^{17}$ the Collaborative Staging Manual and Coding Instructions (2006), ${ }^{18}$ and literature on superficial bladder cancer progression and prognosis ${ }^{13-15,19}$ to subcategorize superficial tumors. Tumors were classified as low risk if they were classified according to TNM criteria as Ta, were grade 1 or 2 , and were $\leq 3 \mathrm{~cm}$. Tumors which were T1or Tis, grade 3 or 4 , or $>3 \mathrm{~cm}$ were classified as moderate/high-risk. ${ }^{13-15,19} \mathrm{We}$ grouped moderate and high risk tumors together because recommended surveillance 
follow-up is similar. ${ }^{13,20}$ Tumors were classified as unknown risk if there were missing data on one or more of the risk level criteria (Appendix A). In summary, our 3 major sub-groupings for those diagnosed with superficial disease were: low-risk superficial (Ta, grade $1-2$, and $\leq 3 \mathrm{~cm}$ ), moderate/high risk superficial (Tis or $\mathrm{T} 1$, grade $2-4$, or $>3 \mathrm{~cm}$ ), and unknown risk superficial disease.

AJCC stage II, stage III, or stage IV cancers were not further sub-divided as these tumors are more homogenous within stage with respect to survival. It is not possible to determine if those with 'localized' as their EOD designation were diagnosed with stage I, stage II, or early stage III disease. ${ }^{21}$ Thus, those whose EOD was coded as 'localized' and not further specified $(n=1316)$ were excluded from the analysis. The SEER program classifies tumor grade in 4 categories. As grade 3 and grade 4 tumors are both considered markers of poor prognosis ${ }^{22}$ we collapsed these categories.

\section{Other covariates}

Overall health was measured by assessing the severity of comorbid conditions via the Charlson comorbidity score. We used Medicare inpatient and outpatient records for the year previous to the cancer diagnosis to provide each patient with a Charlson comorbidity score, ${ }^{23,}{ }^{24}$ using the Klabunde adaptation ${ }^{25}$ of the Deyo method. ${ }^{26}$ Because this requires a year of data we included only those who were at least 66 years old, a year after they became eligible for Medicare coverage.

The SEER-Medicare database does not include information on individual-level socioeconomic status (SES), therefore we used the percentage of persons in the participants' census tract living below the poverty line as a measure of 'ecologic' SES. Participants were considered to have had any treatment if they received surgery, 
radiation, chemo-, or immunotherapy in the year after bladder cancer diagnosis. Aggressive treatment was defined as receiving radical cystectomy and patients were classified as being treated in a teaching hospital if their records contained a charge for indirect medical education.

Analysis

Differences in the distribution of covariates according to marital status were assessed by conducting two-sided Chi-square tests. Differences in survival were assessed via two-sided Kaplan-Meier log-rank tests.

Treatment. To test the hypothesis put forth by other authors that married cancer patients may receive different treatment than unmarried ones, ${ }^{6}$ logistic regression models with any treatment or aggressive treatment as the outcome were constructed adjusting on covariates. Because it is generally not indicated, models assessing aggressive treatment were not constructed for those with superficial disease.

Survival. Cox proportional hazard models were constructed to assess overall 5year survival by gender. We hypothesized a priori that the relationship between marriage and survival would differ according to stage at diagnosis. ${ }^{27}$ We were particularly interested in possible differences between superficial and later stage bladder cancer because those with low stage disease often require long-term and repeated surveillance for recurrence. ${ }^{13,20}$ Therefore, in addition to conducting analyses adjusting for stage in the model, we constructed separate models for each stage. We also conducted analyses collapsing stage into two groups: superficial and stage II-IV, to improve our power to detect small affects. 
We first constructed unadjusted Cox models and then age-adjusted models. We added race and tumor grade and then constructed models, by sequentially adding covariates - comorbidity score, receipt of any (or aggressive) treatment, socioeconomic status, and being seen at a teaching hospital - to assess if improved overall health, differences in treatment, improved resources, or quality of care might be responsible for survival differences by marital status. Age was treated as a time-dependent variable and we calculated $p$-values for the effect of marriage in the full models accounting for multiple comparisons using the Bonferroni correction.

The analyses were conducted using SAS version 9.1.3 (SAS Institute, Inc. Cary, North Carolina) and SAS-callable SUDAAN version 9.0.1 (Research Triangle Institute, Research Triangle, North Carolina) to account for possible auto correlation of observations within SEER areas. This research was approved by the institutional review board at the Harvard School of Public Health.

\section{Results}

A larger proportion of men than women were married in this sample. In total, $11,150(75.2 \%)$ men were married and 1,828 (35.4\%) women were married (Table 1). Age-standardized prevalence estimates of marriage by sex were similar $(74.9 \%$ for men and 37.9 for women) (data not shown). 
Table 1. Distribution of Individual and Tumor Characteristics by Marital Status, SEER-Medicare 19921998 ( $N=19,982)$

\begin{tabular}{|c|c|c|c|c|c|c|}
\hline & \multicolumn{2}{|c|}{$\operatorname{Men}(\mathrm{N}=14,820)$} & \multicolumn{4}{|c|}{ Women $(\mathrm{N}=5,162)$} \\
\hline & $\begin{array}{c}\text { Unmarried(\%) } \\
(\mathrm{N}=3,670)\end{array}$ & $\begin{array}{l}\text { Married }(\%) \\
(\mathrm{N}=11,150)\end{array}$ & $\begin{array}{l}\chi^{2} \mathrm{p}- \\
\text { value }\end{array}$ & $\begin{array}{l}\text { Unmarried(\%) } \\
\qquad(\mathrm{N}=3334)\end{array}$ & $\begin{array}{c}\text { Married }(\%) \\
(\mathrm{N}=1,828)\end{array}$ & $\begin{array}{l}\chi^{2} \mathrm{p}- \\
\text { value }\end{array}$ \\
\hline Race & & & $<0.0001$ & & & $<0.0001$ \\
\hline White & 91.6 & 92.9 & & 89.6 & 91.5 & \\
\hline Black & 5.0 & 2.4 & & 6.7 & 3.3 & \\
\hline Other & 3.5 & 4.8 & & 3.7 & 5.1 & \\
\hline Age & & & $<0.0001$ & & & $<0.0001$ \\
\hline $66-69$ & 17.7 & 22.7 & & 11.7 & 25.3 & \\
\hline $70-74$ & 22.4 & 29.0 & & 18.5 & 31.5 & \\
\hline $75-70$ & 21.7 & 24.3 & & 21.6 & 23.4 & \\
\hline $80+$ & 38.2 & 24.1 & & 48.2 & 19.9 & \\
\hline Stage & & & $<0.0001$ & & & $<0.0001$ \\
\hline Superficial & 72.6 & 78.7 & & 69.5 & 76.6 & \\
\hline (Low risk) & $(9.1)$ & $(10.4)$ & & $(9.3)$ & $(10.7)$ & \\
\hline (Mod/high risk) & $(41.8)$ & $(44.5)$ & & (39.6) & (41.6) & \\
\hline (Unknown risk) & $(21.7)$ & $(23.8)$ & & $(20.6)$ & $(24.3)$ & \\
\hline Stage II - IV & 27.4 & 21.3 & & 30.5 & 23.4 & \\
\hline (Stage II) & (14.8) & $(11.0)$ & & $(17.3)$ & $(12.6)$ & \\
\hline (Stage III) & $(7.7)$ & $(6.6)$ & & $(7.0)$ & $(4.7)$ & \\
\hline (Stage IV) & $(5.0)$ & $(3.7)$ & & $(6.2)$ & $(6.1)$ & \\
\hline Grade & & & 0.008 & & & $<0.0001$ \\
\hline 1 & 13.2 & 15.0 & & 14.6 & 18.9 & \\
\hline 2 & 38.9 & 40.2 & & 35.5 & 39.4 & \\
\hline 3 & 33.7 & 31.3 & & 35.1 & 28.7 & \\
\hline
\end{tabular}




\begin{tabular}{lcccccr}
4 & 8.9 & 8.3 & & 10.6 & 8.3 & \\
Unknown & 5.4 & 5.2 & & 4.2 & 4.7 & \\
Charlson comorbidity score & & & $<0.0001$ & & & $<0.0001$ \\
0 & 69.2 & 74.1 & & 68.6 & 75.9 & \\
1 & 18.7 & 16.6 & & 19.8 & 16.6 & \\
2 & 6.8 & 5.4 & & 6.3 & 4.8 & \\
3 & 5.3 & 4.0 & & 5.3 & 2.8 & \\
Census tract poverty & & & $<0.0001$ & & & $<0.0001$ \\
$<5 \%$ & 33.5 & 40.0 & & 33.9 & 38.7 & \\
$5-9 \%$ & 28.4 & 30.5 & & 29.3 & 31.4 & \\
$10-19 \%$ & 22.6 & 20.6 & & 23.3 & 21.8 & \\
$\geq 20 \%$ & 14.3 & 8.3 & & 12.7 & 7.5 & \\
Missing & 1.1 & 0.7 & & 0.8 & 0.7 & \\
Any treatment & 68.0 & 69.6 & 0.07 & 72.9 & 70.7 & 0.09 \\
Aggressive treatment & 9.9 & 10.7 & 0.2 & 10.6 & 13.5 & 0.002 \\
\hline
\end{tabular}


A significantly larger proportion of married patients were diagnosed with superficial disease in comparison with unmarried patients $\left(78.7 \%\right.$ vs. $72.6 \%, X^{2} P$-value $<0.0001$ among men and $76.6 \%$ vs. $69.5 \% x^{2} P$-value $<0.0001$ among women)(Table 1). In both women and men, those who were married were more likely to have the lowest comorbidity score than those who were unmarried $\left(69.2 \%\right.$ vs. $74.1 \%, X^{2} P$-value $<0.0001$ among men and $68.6 \%$ vs $75.9 \%, x^{2} P$-value $<0.0001$ among women). Additionally, a higher proportion of married patients lived in census tracts where $<5 \%$ of the residents live below the poverty line $(40.0 \%$ vs. $33.5 \%$ among men and $38.7 \%$ vs. $33.9 \%$ among women, both $x^{2} P$-values $\left.<0.0001\right)$.

In a logistic regression model adjusting for age, race, comorbidity score, ecologic SES, and stage, there was no difference in the receipt of any treatment between married and unmarried women (Odds Ratio $[\mathrm{OR}]=0.98,95 \%$ Confidence Interval $[\mathrm{Cl}]=$ 0.77 - 1.24) (Table 2). In fully adjusted models, no statistically significant differences in the receipt of aggressive treatment between married and unmarried women were observed (data not shown). These findings were consistent across stage.

Overall, married men were more likely to receive any treatment than unmarried men $(\mathrm{OR}=1.17,95 \% \mathrm{Cl}=1.05-1.30)$ (Table 2$)$. In stage-specific models, this result persists for those with stage II $(\mathrm{OR}=1.59,95 \% \mathrm{Cl}=1.11-2.26)$, stage III $(\mathrm{OR}=1.68$, $95 \% \mathrm{Cl}, 1.05-2.67)$, or stage IV $(\mathrm{OR}=1.69,95 \% \mathrm{Cl}=1.07-2.67)$ disease. Married men were no more likely than unmarried men to receive aggressive treatment, adjusting for stage, age, race, comorbidity score, and ecologic SES (data not shown). 


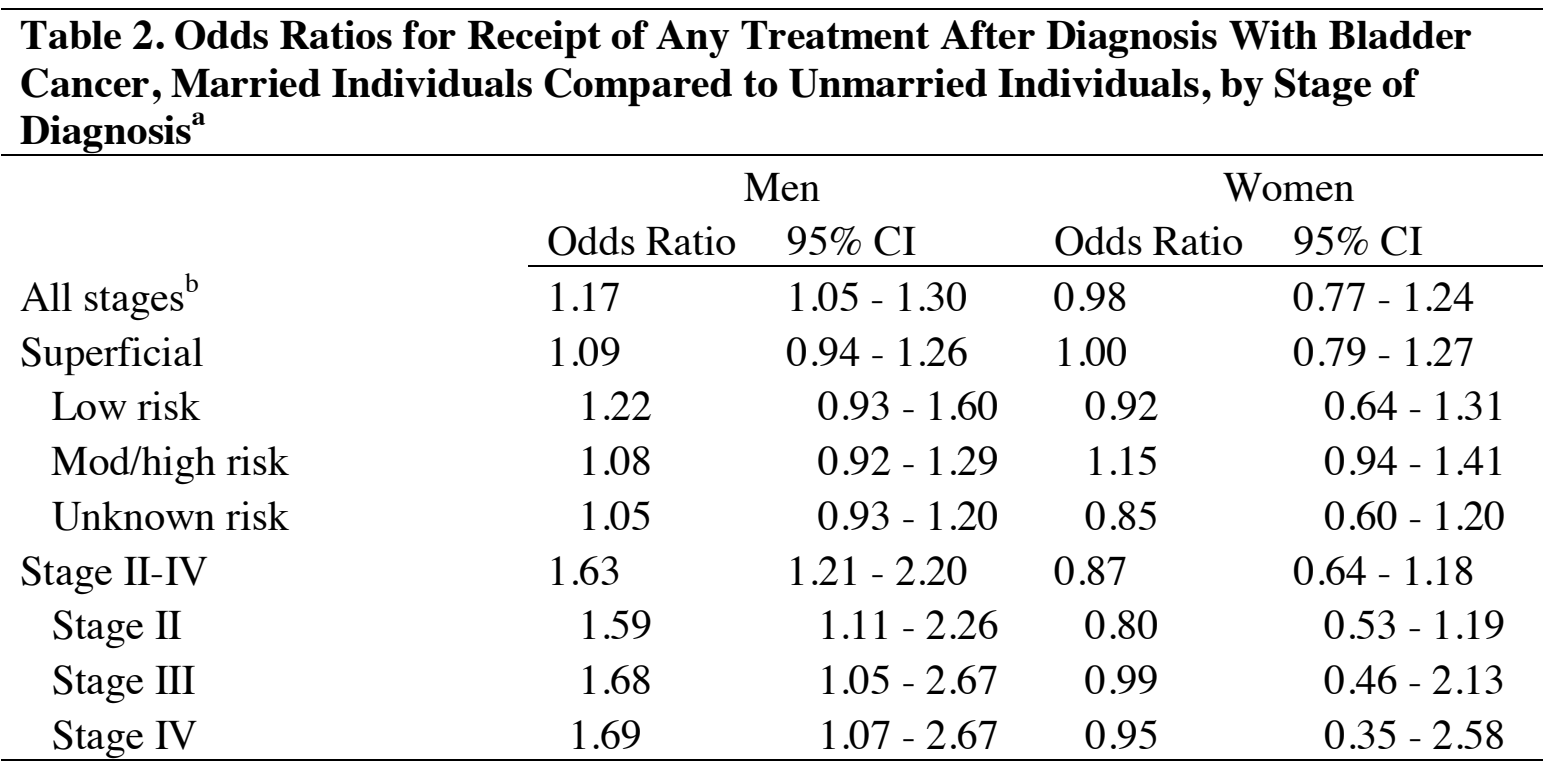

Abbreviation: CI, Confidence interval

${ }^{a}$ Adjusted for age, race, number of comorbidities, and socioeconomic status

${ }^{\mathrm{b}}$ Also adjusted for stage at diagnosis 
Both married men and married women had better survival after diagnosis than their unmarried counterparts (log-rank $P$-values $<0.0001$ ) (Figure 1). In stage-specific Kaplan-Meier analyses married men experienced a survival advantage over unmarried men for each stage at diagnosis (all log-rank $P$-values $<0.0001)$ (data not shown). Among women, married participants experienced a survival advantage over unmarried participants when diagnosed at all stages (all log-rank $P$-values $<0.01$ ) except stage III (log-rank $P$-value 0.19) (data not shown).

In unadjusted survival models, men who were married experienced lower hazards of mortality during the 5 years of follow-up than men who were unmarried (all stage $\mathrm{HR}=0.64,95 \% \mathrm{Cl}=0.59-0.68)($ Table 3 ). In models adjusted for age, married men continued to experience a lower 5-year mortality rate than unmarried men for all stages. This pattern remained when all other covariates were added to the models sequentially to test possible mediators, and when the models were stratified by stage at diagnosis. 
Table 3. Hazard Ratios for Mortality Risk Over 5-Years for Follow-Up Comparing Married to Unmarried Bladder Cancer Patients, by Stage of Diagnosis

\begin{tabular}{|c|c|c|c|c|c|}
\hline & $\begin{array}{l}\text { No. of } \\
\text { deaths }\end{array}$ & $\begin{array}{l}\text { Unadjusted } \\
\text { HR (95\% CI) }\end{array}$ & $\begin{array}{l}\text { Age-adjusted } \\
\text { HR }(95 \% \mathrm{CI})\end{array}$ & $\begin{array}{l}\text { Full Model }^{\mathrm{a}} \\
\text { HR }(95 \% \mathrm{CI})\end{array}$ & $\begin{array}{l}\text { Full Model } \\
\text { p-value }\end{array}$ \\
\hline \multicolumn{6}{|l|}{ Female } \\
\hline All stages ${ }^{b}$ & 2241 & $0.56(0.49-0.63)$ & $0.73(0.65-0.82)$ & $0.83(0.75-0.92)$ & $0.002^{\star}$ \\
\hline Superficial & 1161 & $0.49(0.41-0.60)$ & $0.69(0.56-0.84)$ & $0.72(0.62-0.84)$ & $0.001 *$ \\
\hline Low risk & 112 & $0.52(0.34-0.79)$ & $0.86(0.56-1.33)$ & $0.89(0.55-1.44)$ & 0.6 \\
\hline Mod/High risk & 731 & $0.47(0.32-0.69)$ & $0.67(0.55-0.81)$ & $0.71(0.60-0.85)$ & $0.001 *$ \\
\hline Unknown risk & 318 & $0.47(0.32-0.69)$ & $0.67(0.49-0.91)$ & $0.69(0.56-0.86)$ & $0.003 *$ \\
\hline Stage II-IV ${ }^{\mathrm{b}}$ & 1080 & $0.77(0.69-0.87)$ & $0.90(0.82-0.99)$ & $0.96(0.87-1.07)$ & 0.43 \\
\hline Stage II & 554 & $0.71(0.56-0.89)$ & $0.87(0.73-1.03)$ & $0.96(0.82-1.12)$ & 0.58 \\
\hline Stage III & 245 & $0.82(0.60-1.14)$ & $1.10(0.75-1.63)$ & $1.17(0.71-1.93)$ & 0.50 \\
\hline Stage IV & 281 & $0.74(0.52-1.07)$ & $0.92(0.71-1.20)$ & $0.93(0.68-1.27)$ & 0.60 \\
\hline \multicolumn{6}{|l|}{ Male } \\
\hline All stages ${ }^{b}$ & 6206 & $0.64(0.59-0.68)$ & $0.76(0.70-0.83)$ & $0.80(0.74-0.87)$ & $0.0001 *$ \\
\hline Superficial & 3812 & $0.65(0.60-0.70)$ & $0.77(0.69-0.87)$ & $0.84(0.78-0.90)$ & $0.0001 *$ \\
\hline Low risk & 385 & $0.70(0.57-0.85)$ & $0.68(0.55-0.84)$ & $0.70(0.57-0.86)$ & $0.003 *$ \\
\hline Mod/High risk & 2386 & $0.83(0.76-0.91)$ & $0.83(0.76-0.91)$ & $0.83(0.76-0.90)$ & $0.0006^{*}$ \\
\hline Unknown risk & 1127 & $0.90(0.81-0.99)$ & $0.89(0.80-0.99)$ & $0.90(0.80-1.00)$ & 0.07 \\
\hline Stage II-IV ${ }^{b}$ & 2394 & $0.70(0.62-0.78)$ & $0.77(0.69-0.87)$ & $0.78(0.69-0.89)$ & $0.001 *$ \\
\hline Stage II & 733 & $0.78(0.68-0.89)$ & $0.77(0.68-0.88)$ & $0.77(0.67-0.89)$ & $0.002 *$ \\
\hline Stage III & 534 & $0.82(0.69-0.97)$ & $0.81(0.69-0.96)$ & $0.83(0.69-1.00)$ & 0.05 \\
\hline Stage IV & 1041 & $0.70(0.56-0.88)$ & $0.68(0.57-0.80)$ & $0.71(0.58-0.85)$ & $0.002 *$ \\
\hline \multicolumn{6}{|c|}{$\begin{array}{l}\text { Abbreviations: HR, Hazard Ratio; CI, Confidence Interval } \\
\text { *p-value remains significant at the } 0.05 \text { level after Bonferroni correction }\end{array}$} \\
\hline
\end{tabular}


In models where stage, grade, race, comorbidity score, receipt of any treatment, ecologic SES, and teaching hospital designation were added to the model sequentially to test possible mechanisms, married women had $17 \%$ lower 5 -year hazard of mortality than unmarried women. However, in stage-specific models marital status remained significant in fully adjusted models for only those with superficial disease. Among those in the combined stage II-IV category, the addition of age and comorbidity score to the model explained the association of marital status and survival $(\mathrm{HR}=0.98,95 \% \mathrm{Cl}=0.89-$ 1.07) (data not shown).

\section{Discussion}

Previous studies indicate marital status influences survival after diagnosis with bladder cancer. ${ }^{7}$ The results of the current study's tests to assess the mechanism by which marriage might confer a survival benefit showed that treatment, comorbidities, socioeconomic status, and accessing a teaching hospital could not explain the association in men or women with superficial disease, thus suggesting that those who are married in these groups are benefiting from something other than these factors, perhaps practical care and/or social support. Among women with stage II-IV disease, age and comorbid conditions explain the association between marital status and improved survival. Additionally, the results suggest, after accounting for sociodemographic and clinical factors, men may experience a greater survival benefit from marriage after diagnosis with later stage bladder cancer than women.

Though it was not directly measured in this study, the finding that the association between marital status and cancer survival is stronger among women who 
are diagnosed with moderate/high-risk superficial bladder cancer than in women who are diagnosed with low-risk superficial bladder cancer is consistent with the notion that marital status improves survival through increased social or practical support. Though most patients likely benefit emotionally and practically from social support regardless of the stage at which they are diagnosed, patients with moderate/high-risk superficial bladder cancer face unique challenges. Thirty to 50 percent of moderate/high-risk superficial bladder cancers progress, even with treatment ${ }^{15,20}$ requiring rigorous management in the form of surveillance cystoscopy every 3 months for 12 to 24 months after treatment, every 6 months after that to 5 years, and every 12 months to 10 years. ${ }^{13,20}$ A study by Sox et al. reported married patients were more likely to have a primary care physician than unmarried patients, ${ }^{27}$ and that having a relationship with one was a stronger predictor of health care access than even having insurance. This improved access might influence the likelihood of both adhering to surveillance and maintaining good health. It is also possible that practical support, in the form of transportation or scheduling appointments, for example, provided by a spouse could prove beneficial in adhering to the surveillance schedule and improve survival.

Social support may also improve cancer survival via several biologic pathways including ones that can lead to alterations in the functioning of the endocrine or immune systems. ${ }^{28}$ Emotional stress can trigger a fight-or-flight response by the autonomic nervous system (ANS) or a defeat/withdrawal response by the hypothalamic-pituitaryadrenal (HPA) axis. ${ }^{29}$ Marital disruption, bereavement, and depression are all associated with changes in the HPA axis and ANS. ${ }^{30,31}$ These changes can result in 
compromised DNA repair, increased angiogenesis, and decreases in Natural Killer (NK) cell function, which play a role in surveillance for cancer tumor cells. ${ }^{29}$

Studies on the influence of marriage on all-cause mortality have found that the mechanisms can be different for men and women. ${ }^{1}$ The fact that marriage seems to be more protective in men with advanced bladder cancer than among those with superficial bladder cancer (the opposite trend as among women in this study) suggest that there are likely additional unmeasured mediators of the association between survival and bladder cancer. None of the results directly suggest a particular pathway to us and future research would be necessary to further elucidate what they might be.

That the influence of marriage on cancer survival might be stronger in men has been reported in other studies. In a study of head and neck cancer patients enrolled in Radiation Therapy Oncology Group (RTOG) clinical trials, investigators reported no survival difference between married and unmarried women, though they did observe a difference in men. ${ }^{32}$ Another study, regarding bladder cancer survival in Norway, found men who were never-married or widowed experienced higher mortality than those who were married, when in women no survival difference was observed. ${ }^{6}$ Though that study assessed the influence of treatment on survival, it did not assess the influence of health status or quality of treatment facility, adjusted only crudely for stage, and included individuals for whom bladder cancer was not the first cancer diagnosis. ${ }^{6}$

Though we were able to asses the influence of previously unexplored mediators, the current analysis is constrained by the available data. SEER-Medicare data lack information on cohabitation, marital quality, or changes in marital status, all of which 
may be associated with differences in longevity. ${ }^{1,32,33}$ As stated earlier, the SEERMedicare database does not contain information on individual SES which necessitated the use of a proxy, 'ecologic' SES. It is possible that our results may be explained in part by residual confounding due to the use of the proxy measure instead of individual level SES. It is also possible that patients may have moved after diagnosis, which could result in misclassification of socioeconomic status during survival time. Because there could be many reasons for changing residence, both related and unrelated to the patient's illness, it is not clear in which direction the bias caused by this type of misclassification might be. The patient's spouse's SES might also be an important covariate to measure in future studies. However, this might be more important in investigations of marital status and cardiovascular-related mortality than for cancer-related mortality. ${ }^{34}$

The SEER-Medicare database only represents those who have survived to the age of 65 and are therefore likely to be healthier than the general population. However, since the majority of bladder cancers are diagnosed after $65,{ }^{8}$ we do not believe this would greatly impact the validity of our results. Another limitation of the study is the lack of direct measures of social/practical support or cancer-related behaviors. Though we tested most of the prevailing theories explaining the relation between marital status and cancer survival, we were unable to directly test the influence of social or practical support. However, the present findings are consistent with a situation in which social or practical support is conferring mortality protection: ${ }^{1}$ we see the benefit in men and only in women with stages of disease that would most likely require practical or social support. 
Additionally, though we were able to assess overall health status, we were unable to assess individual health behaviors. Though $50 \%$ to $60 \%$ of bladder cancers are attributable to cigarette smoking, ${ }^{15}$ it is unclear if smoking cessation after diagnosis improves survival. ${ }^{35}$ If smoking cessation did improve survival after diagnosis, and married patients were more likely to quit, this might also be a mediator through which marriage confers protection. Differential levels of physical activity according to marital status may also be a possible unexplored mediator through which marriage improves survival. ${ }^{36}$

An additional potential limitation is the possibility that our null findings are not true null findings, but that we are simply underpowered to detect an association. Therefore, conclusions about the different influence marital status may have on men and women should be made with some caution.

This study also had a number of strengths, including the ability to assess the influence of a broad range of covariates. Unlike previous studies, we were able to assess some of the possible mediating processes explaining the association between marriage and cancer survival. A further strength of the study is the large sample size. This improved our ability to assess the influence of multiple covariates simultaneously and to assess the association of marriage and cancer survival for men and women separately. This is of particular importance since the survival benefit of marriage may differ according to sex. The detailed level of the data also permitted us to assess the relationships in low-risk and moderate/high-risk superficial patients separately. Physicians differentiate these types of disease clinically and we found that among women marriage may influence survival differentially as well. 
The incidence of bladder cancer rises with age and hence the burden of bladder cancer in the U.S. will increase as the population ages. There are currently no population-wide screening tests available for bladder cancer. Therefore, it is of particular importance to understand factors that improve survival after diagnosis. We found marital status to be an independent prognostic indicator of survival. Although marital status itself is not amenable to intervention, pathways through which marriage improves cancer survival - for example, through provision of social support - may be potentially packaged and delivered through interventions. Although recent randomized controlled trials have not found that provision of social support improves survival among women with advanced breast cancer ${ }^{37}$, we cannot discount the possibility that social support interventions may improve the prognosis of other types of cancer. 
Appendix A. Categorization of superficial bladder cancer $(\mathrm{N}=15,158)$ Low Risk $(\mathrm{n}=2002) \quad$ Moderate and High Risk $(\mathrm{n}=8574)$

Ta, Grade $1, \leq 3 \mathrm{~cm}(\mathrm{n}=676) \quad$ Ta, Grade 1, $>3 \mathrm{~cm}(\mathrm{n}=150)$

Unknown Risk $(\mathrm{n}=4582)$

Ta, Grade $2, \leq 3 \mathrm{~cm}(n=1326) \quad$ Ta, Grade 2, $>3 \mathrm{~cm}(n=473)$

Ta, Grade 1, unknown size $(n=1372)$

Ta, Grade 2, unknown size $(n=2842)$

Ta, Grade 3, any size $(n=1167)$

Ta, unknown Grade, unknown size $(\mathrm{n}=$

Ta, Grade 4, any size $(n=134)$

Ta, unknown Grade, $\leq 3 \mathrm{~cm}(\mathrm{n}=81)$

T1, any grade $(n=5750)$

Ta, unknown Grade, $>3 \mathrm{~cm}(\mathrm{n}=21)$

Tis $(n=900)$ 


\section{References}

1. Lillard L, Waite L. "Til Death Do Us Part: Marital Disruption and Mortality. American Journal of Sociology 1995;100(5):1131-56.

2. Minino A, Heron M, Murphy S, Kochankek K, Deaths: Final Data for 2004. National Center for Health Statistics, 2007.

3. Eriksen KT, Petersen A, Poulsen AH, Deltour I, Raaschou-Nielsen O. Social inequality and incidence of and survival from cancers of the kidney and urinary bladder in a population-based study in Denmark, 1994-2003. Eur J Cancer 2008;44(14):203042.

4. Goodwin JS, Hunt WC, Key CR, Samet JM. The effect of marital status on stage, treatment, and survival of cancer patients. Jama 1987;258(21):3125-30.

5. Krongrad A, Lai H, Burke MA, Goodkin K, Lai S. Marriage and mortality in prostate cancer. J Urol 1996;156(5):1696-70.

6. Kravdal O. The impact of marital status on cancer survival. Soc Sci Med 2001;52(3):357-68.

7. Gore J, Kwan L, Saigal C, Litwin M. Marriage and Mortality in Bladder Carcinoma. Cancer 2005; 104:1188-94.

8. SEER Cancer Statistics Review. Surveillance Research Program. National Cancer Institute, 1973-2005.

9. American Cancer Society. Cancer Facts \& Figures for African Americans 2003-2004. American Cancer Soiety, 2008.

10. Iwashyna TJ, Christakis NA. Marriage, widowhood, and health-care use. Soc Sci Med 2003;57(11):2137-47. 
11. Warren JL, Klabunde CN, Schrag D, Bach PB, Riley GF. Overview of the SEERMedicare data: content, research applications, and generalizability to the United States elderly population. Med Care 2002;40(8 Suppl):IV-3-18.

12. Potosky A, Riley G, Lubitz J. Potential for cancer related health services research using a linked Medicare-tumor registry database. Med Care 1993;31:732-48.

13. Pow-Sang J, Seigne J. Contemporary Management of Superficial Bladder Cancer. Cancer Control 2000;7(4):335-39.

14. Lee R, Droller MJ. The natural history of bladder cancer. Implications for therapy. Urol Clin North Am 2000;27(1):1-13, vii.

15. Pashos C, Botteman M, Laskin B, Redaelli A. Bladder Cancer: Epidemiology, Diagnosis, and Management. Cancer Pract 2002;10(6):311-22.

16. Fritz A, Ries L. (Eds). The SEER Program Code Manual: U.S. Department of Health and Human Services, 1998.

17. Greene F, Page D, Fleming I, Fritz A, Balch C, Haller D, et al. (Eds).AJCC Cancer Staging Manual, ed. 6: Springer, 2002:435.

18. Collaborative Staging Task Force of the American Joint Committee on Cancer. Collaborative Staging Manual and Coding Instructions, version 01.03.00. Jointly published by American Joint Comittee on Cancer (Chicago, IL) and U.S. Department of Health and Human Services (Bethesda, MD). Incorporates updates through September 8, 2006.

19. Kurth KH, Denis L, Bouffioux C, Sylvester R, Debruyne FM, Pavone-Macaluso M, et al. Factors affecting recurrence and progression in superficial bladder tumours. Eur $J$ Cancer 1995;31A(11):1840-6. 
20. Smith J, Labasky R, Cockett A, Fracchia J, Montie J, Rowland R, Report on the Management of Non-Muscle-Invasive Bladder Cancer (stages Ta, T1, and Tis). American Urological Association Inc., 1999.

21. SEER Program. Cancer Statistics Branch. National Cancer Institute. SEER Program: Comparative Staging Guide For Cancer. Version 1.1: U.S. Department of Health and Human Service, 1993.

22. Kaubisch S, Lum BL, Reese J, Freiha F, Torti FM. Stage T1 bladder cancer: grade is the primary determinant for risk of muscle invasion. $J$ Urol 1991;146(1):28-31. 23. Charlson ME, Pompei P, Ales KL, MacKenzie CR. A new method of classifying prognostic comorbidity in longitudinal studies: development and validation. J Chronic Dis 1987;40(5):373-83.

24. Charlson ME, Sax FL, MacKenzie CR, Braham RL, Fields SD, Douglas RG, Jr. Morbidity during hospitalization: can we predict it? J Chronic Dis 1987;40(7):705-12. 25. Klabunde CN, Potosky AL, Legler JM, Warren JL. Development of a comorbidity index using physician claims data. J Clin Epidemiol 2000;53(12):1258-67. 26. Deyo R, Cherkin D, Ciol M. Adapting A Clinical Comorbidity Index For Use With ICD-9-CM Administrative Database. J Clin Epidemiol 1992;45(6):613-19.

27. Sox CM, Swartz K, Burstin HR, Brennan TA. Insurance or a regular physician: which is the most powerful predictor of health care? Am J Public Health 1998;88(3):364-70. 28. Spiegel D. Mind matters. Coping and cancer progression. J Psychosom Res 2001;50(5):287-90. 
29. Antoni MH, Lutgendorf SK, Cole SW, Dhabhar FS, Sephton SE, McDonald PG, et al. The influence of bio-behavioural factors on tumour biology: pathways and mechanisms. Nat Rev Cancer 2006;6(3):240-8.

30. Kiecolt-Glaser JK, McGuire L, Robles TF, Glaser R. Emotions, morbidity, and mortality: new perspectives from psychoneuroimmunology. Annu Rev Psychol 2002;53:83-107.

31. McEwen BS. Allostasis and allostatic load: implications for neuropsychopharmacology. Neuropsychopharmacology 2000;22(2):108-24.

32. Konski A, Pajak T, Movsas B, Coyne J, Harris J, Gwede C, et al. Disadvantage of Men Living Alone Participating in Radtiation Therapy Oncology Groups Head and Neck Trials. J Clin Oncol 2006;24:4177-83.

33. Abbey A, Andrews FM, Halman LJ. Provision and receipt of social support and disregard: what is their impact on the marital life quality of infertile and fertile couples? $J$ Pers Soc Psychol 1995;68(3):455-69.

34. Skalicka V, Kunst AE. Effects of spouses' socioeconomic characteristics on mortality among men and women in a Norwegian longitudinal study. Soc Sci Med 2008;66(9):2035-47.

35. Aveyard P, Adab P, Cheng K, Wallace D, Hey K, Murphy M. Does smoking status influence the prognosis of bladder cancer? A systematic review. BJU International 2002;90:228-39.

36. Hamer M, Stamatakis E, Saxton JM. The impact of physical activity on all-cause mortality in men and women after a cancer diagnosis. Cancer Causes Control 2008. 
37. Spiegel D, Butler LD, Giese-Davis J, Koopman C, Miller E, DiMiceli S, et al. Effects of supportive-expressive group therapy on survival of patients with metastatic breast cancer: a randomized prospective trial. Cancer 2007;110(5):1130-8. 

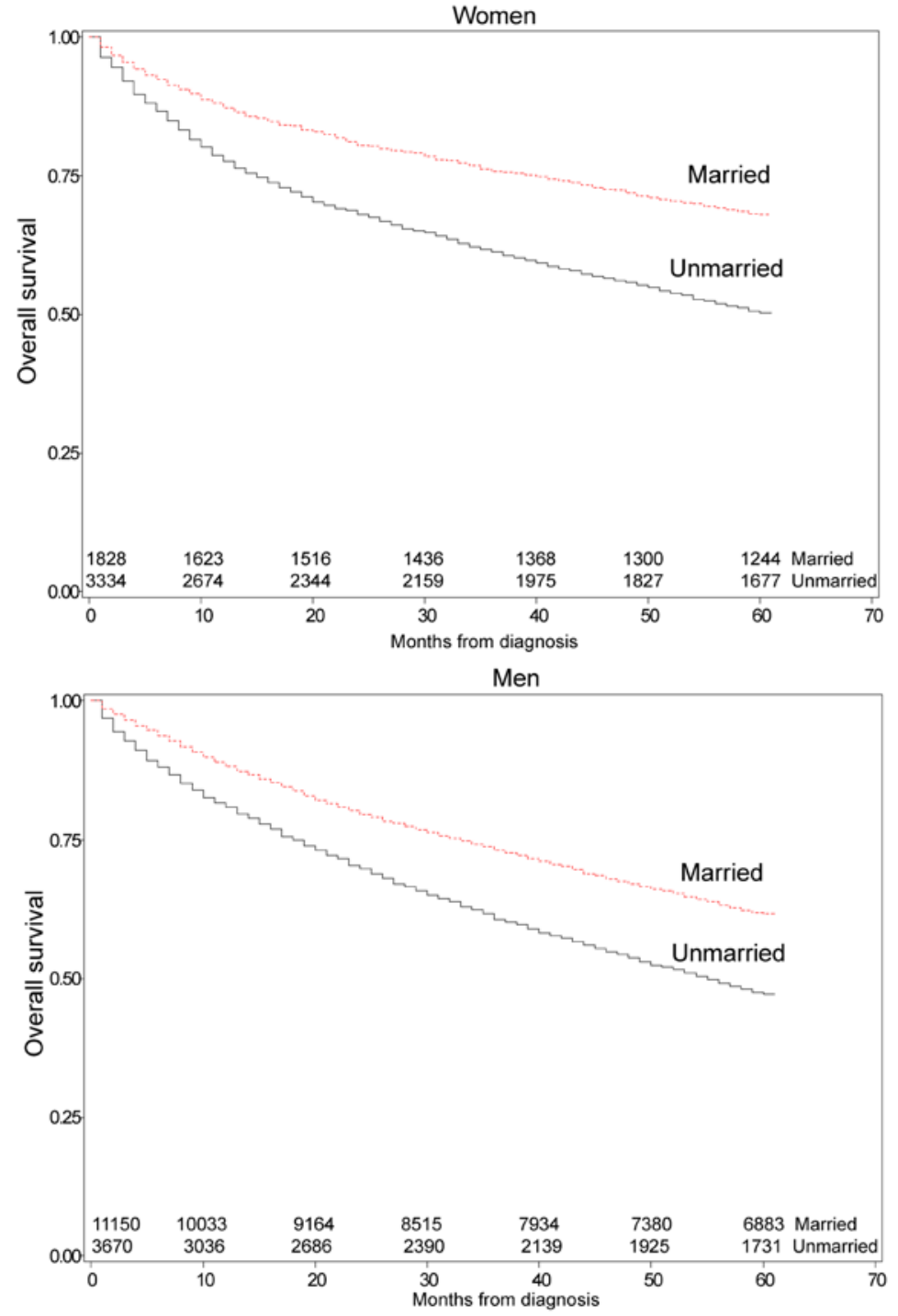

Figure 1. Overall survival according to marital status. The Kaplan-Meier curves differ significantly (both log-rank $p<0.0001$ ). 